\title{
A Bridge Too Far: Testing the Limits of Polypyridyl Ligands in Bridging Soluble Subunits of a Coordination Polymer
}

Samuel V. F. Beddoe, ${ }^{\dagger}$ Anthony J. Fitzpatrick, ${ }^{\ddagger \S}$ Jason R. Price, ${ }^{\perp}$ Neil Mallo," Jonathon E. Beves,,$"$ Grace G. Morgan, ${ }^{\ddagger}$ Jonathan A. Kitchen ${ }^{\dagger}$ and Tony D. Keene ${ }^{\dagger \neq *}$

${ }^{\dagger}$ Chemistry, University of Southampton, University Road, Highfield, Southampton, SO17 1BJ, UK.

${ }^{\ddagger}$ School of Chemistry, University College Dublin, Belfield, Dublin 4, Ireland.

${ }^{\S}$ School of Science and Technology, Nottingham Trent University, Nottingham, NG11 8NS, UK.

${ }^{\perp}$ Australian Synchrotron, 800 Blackburn Road, Clayton, VIC 3198, Australia.

"School of Chemistry, University of New South Wales, Sydney, NSW 2052, Australia.

\begin{abstract}
Starting with a coordination polymer, $\left\{[\mathrm{Cu}(\mathbf{L})]_{2}\right\}_{n}$ ( $\mathbf{1}$ where $\mathrm{H}_{2} \mathrm{~L}=$ salicylidene-2-aminophenol), we have explored the ability of polypyridyl ligands $(\mathbf{P})$ to bridge the monomer complex to form nine $\left\{[\mathrm{Cu}(\mathbf{L})]_{2}(\mathbf{P})\right\}$ complexes. The identity and solution stability of the $[\mathrm{Cu}(\mathrm{L})]$ units has been investigated through a novel combined UV-vis/EPR experiment and it has been found to be a stable supramolecular building unit for the construction of discrete complexes and coordination polymers. The reorganisation of $[\mathrm{Cu}(\mathrm{L})]$ units to a new coordination polymer on addition of 4,4'-bipyridine markedly changes the connectivity of the structure and the magnitude of the antiferromagnetic interactions through reorientation of the $\mathrm{Cu}(\mathrm{II})$ orbitals. We also present the structure of 1,80 years after its synthesis was first reported.
\end{abstract}

\section{Introduction}

A key step in the rational design of coordination polymers is the control of linkages between metal centres. This allows for the rational design of specific structural motifs and inclusion of chemical properties in materials such as metal-organic frameworks (MOFs) ${ }^{1-3}$ and polyhedra (MOPs). ${ }^{4,5}$ Polypyridyls have been shown to be an important class of ligand in linkage control. ${ }^{6-10}$ Our previous work has shown that polypyridyls influence a range of properties in MOFs, such as molecular magnetism and anomalous thermal expansion and also play an important role in structure direction. ${ }^{11,12}$ Polypyridyls can be utilised to construct stable secondary building units for MOF formation, ${ }^{13}$ to provide functional groups for the post synthetic modification of frameworks ${ }^{14}$ and to tune spin crossover properties, ${ }^{15-17}$ making them a particularly versatile family of ligands.

Another important class of ligands are Schiff bases, which are some of the most versatile ligands in coordination chemistry, ${ }^{18}$ combining ease of synthesis (most are formed by simple condensation of an amine and an aldehyde or ketone) with a vast range of constituent functional groups. This leads to complexes that can be utilised as catalysts, ${ }^{19,20}$ as structure-directing components in supramolecular assemblies ${ }^{21-23}$ and as single-molecule magnets (SMMs). ${ }^{24-26}$ The ability to build Schiff bases with multiple coordination sites allows for the formation of coordination polymers, such as MOFs with heterogeneous catalytic properties. ${ }^{27-29}$

We have begun to focus efforts on investigating the synthesis and properties of soluble coordination polymers and the potential to use them as a base to synthesise new materials. We selected the simple Schiff base salicylidene-2-aminophenol $\left(\mathrm{H}_{2} \mathrm{~L}\right)$ on the basis that it has previously produced $\mathrm{SMMs},{ }^{30-32}$ clusters ${ }^{33-35}$ and coordination polymers. ${ }^{36}$ This ligand can also form discrete species with ancillary ligands ${ }^{37}$ and replacement of the latter with bridging ligands may potentially lead to coordination polymers. The versatility of closely related Schiff bases has been demonstrated in a number of fields, such as SMMs, ${ }^{38-40}$ metal extraction agents ${ }^{41}$ and liquid crystals, ${ }^{42}$ making $\mathrm{H}_{2} \mathrm{~L}$ an excellent starting point. 
Complexes of $\mathrm{Cu}(\mathrm{II})$ and $\mathrm{L}^{2-}$ have been studied since at least $1937^{43}$ resulting in extensive characterisation of room temperature magnetic properties in an attempt to elucidate the structure ${ }^{44-}$ ${ }^{46}$ which we can now report. We investigated the solubility of the complex to produce a soluble $[\mathrm{Cu}(\mathrm{L})]$ secondary building unit (SBU) for the synthesis of more complex coordination polymer species. We used a range of polypyridyl bridging ligands $(\mathbf{P})$ to vary the size, shape and packing interactions of $[\mathrm{Cu}(\mathbf{L})]_{n}(\mathbf{P})$ complexes.
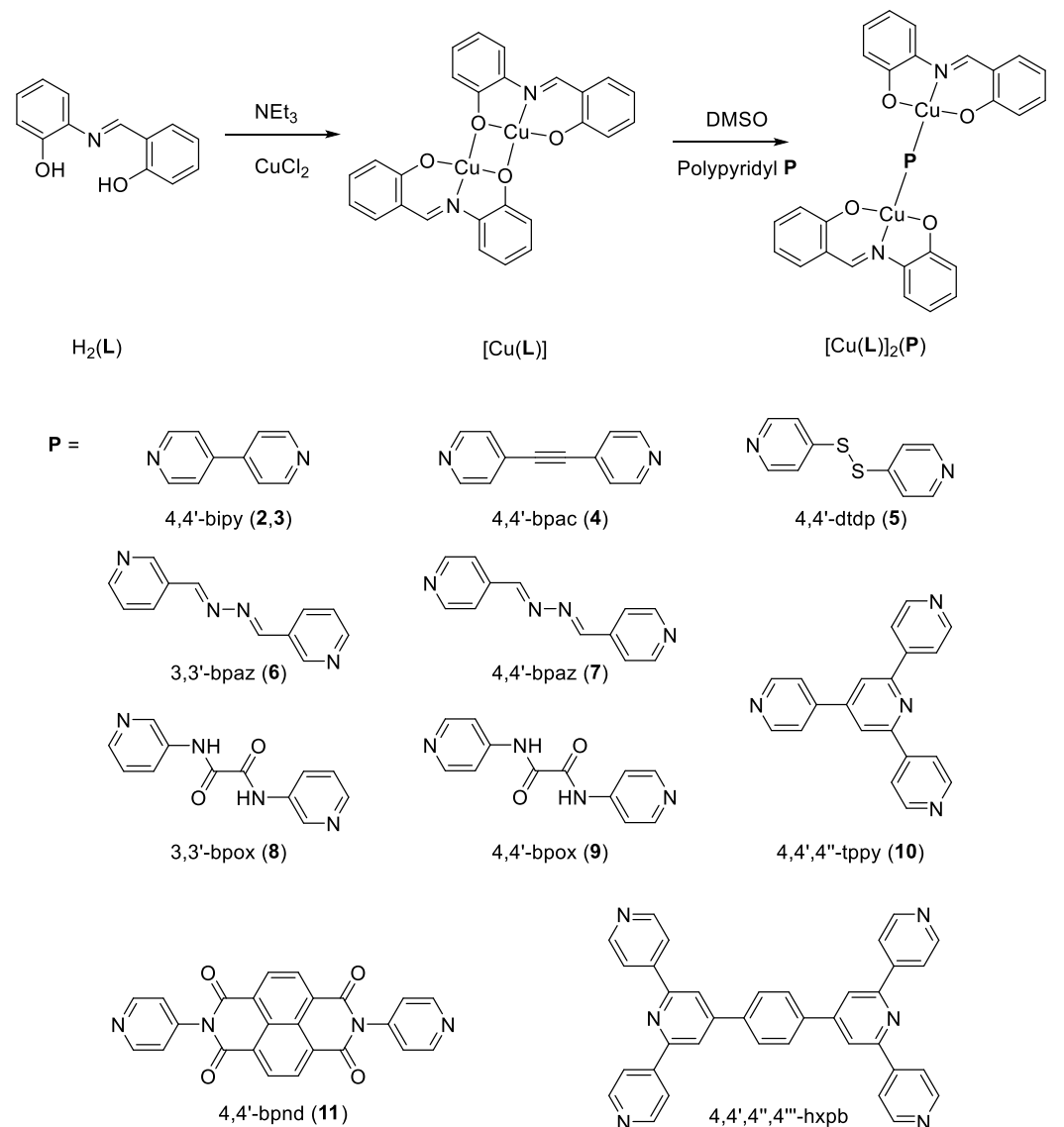

4,4'-bpox (9)

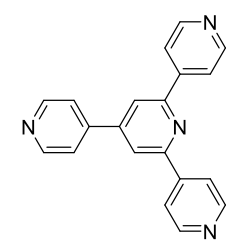

4,4',4"-tppy (10)

Scheme 1: Complexation of $\mathrm{H}_{2} \mathrm{~L}$ with copper(II) and the polypyridyl bridging ligands used in this work. Numbers in bold refer to the complexes and structures produced.

Table 1 Compounds Synthesised In This Work.

\begin{tabular}{|c|c|c|c|c|}
\hline Compound & Ligand & Formula & $\mathrm{Cu} \cdot \cdots \mathrm{Cu} / \AA^{\mathrm{a}}$ & [Cu(L)] Disorder \\
\hline 1 & $\mathrm{n} / \mathrm{a}$ & $\left\{[\mathrm{Cu}(\mathrm{L})]_{2}\right\}_{n}$ & $2.961(6) 2.908(6)$ & 73:27 \\
\hline 2 & 4,4'-bipy & $\left\{[\mathrm{Cu}(\mathrm{L})]_{2}\left(4,4^{\prime}-\text { bipy }\right)\right\}_{n}$ & $11.086(7)$ & 69:31 \\
\hline 3 & 4,4'-bipy & {$[\mathrm{Cu}(\mathrm{L})]_{2}\left(4,4^{\prime}\right.$-bipy) $4 \mathrm{DMSO}$} & $11.112(8)$ & 89:11 \\
\hline 4 & 4,4'-bpac & {$[\mathrm{Cu}(\mathrm{L})]_{2}\left(4,4^{\prime}-\mathrm{bpac}\right)$} & $13.701(5)$ & $55: 45$ \\
\hline 5 & $4,4^{\prime}$-dtdp & {$[\mathrm{Cu}(\mathrm{L})]_{2}\left(4,4^{\prime}-\mathrm{dtdp}\right)$} & $10.439(3)\left[15.081^{b}\right]$ & $50: 50$ \\
\hline 6 & 3,3'-bpaz & {$[\mathrm{Cu}(\mathrm{L})]_{2}\left(3,3^{\prime}-\mathrm{bpaz}\right)$} & $12.625(8)\left[15.289^{c}\right]$ & $54: 46$ \\
\hline 7 & 4,4'-bpaz & {$[\mathrm{Cu}(\mathrm{L})]_{2}\left(4,4^{\prime}-\mathrm{bpaz}\right)$} & $15.357(3)$ & 64:36 \\
\hline 8 & 3,3'-bpox & $\begin{array}{l}\left\{[\mathrm{Cu}(\mathrm{L})]_{2}\left(3,3^{\prime}-\right.\right. \\
\text { bpox })\}_{n} \cdot 4 n \mathrm{DMSO}\end{array}$ & $13.030(12)\left[15.725^{\circ}\right]$ & $75: 27$ / 64:36 \\
\hline 9 & 4,4'-bpox & {$[\mathrm{Cu}(\mathrm{L})(\mathrm{DMSO})]_{2}\left(4,4^{\prime}-\right.$-bpox $)$} & $15.482(6)$ & 65:35 \\
\hline 10 & 4,4',4"-tppy & {$[\mathrm{Cu}(\mathrm{L})]_{2}\left(4,4^{\prime}, 4^{\prime \prime}\right.$-tppy)·DMSO } & $13.387(2)\left[15.343^{\mathrm{d}}\right]$ & $100: 0 / 74: 26$ \\
\hline 11 & 4,4'-bpnd & 4,4'-bpnd $\cdot 2 \mathrm{DMSO}$ & $\mathrm{n} / \mathrm{a}$ & $n / a$ \\
\hline
\end{tabular}

a) Major component only; b) Measured $\mathrm{Cu}-\mathrm{S}-\mathrm{S}-\mathrm{Cu}$; c) Measured $\mathrm{Cu}$-(centroid of py1)- (centroid of py2)-Cu; d) Measured Cu-(centroid of 4,4',4"-tppy)-Cu 


\section{Results and Discussion}

\section{Formation and structure of $\left\{[\mathrm{Cu}(\mathrm{L})]_{2}\right\}_{\mathrm{n}}(1)$.}

We began this work by investigating the production of a simple binary complex of $\mathrm{Cu}(\mathrm{II})$ and $\mathrm{H}_{2} \mathrm{~L}$, leading to compound 1 . This forms rapidly from a solution of $\mathrm{H}_{2} \mathrm{~L}$ and $\mathrm{CuCl}_{2} \cdot 2 \mathrm{H}_{2} \mathrm{O}$ in methanol on addition of triethylamine to give a fine green powder of $\left\{[\mathrm{Cu}(\mathrm{L})]_{2}\right\}_{n}$ and a dark green-brown supernatant. This reaction proceeds in several solvents (DMF, MeCN, EtOH) to give the same product. Recrystallisation of 1 from DMSO affords very small green crystals suitable for single crystal X-ray diffraction. The structure of 1 (Figure 1a) consists of two independent $[\mathrm{Cu}(\mathrm{L})]$ units where the $\mathrm{Cu}$ ions are chelated by L $\mathrm{L}^{2-}$ in the short $d_{x^{2}-y^{2}}$ plane, as denoted by the short $\mathrm{Cu}-\mathrm{N}$ (av. $1.924 \AA$ ) and $\mathrm{Cu}-\mathrm{O}$ bonds (av. 1.873 Å from the salicylidene phenoxide, $\mathrm{O}_{\text {sal, }}$ and $1.956 \AA$ from the aminophenol phenoxide, $\mathrm{O}_{\mathrm{ap}}$ ). There is full-molecule disorder and it can be seen in Figure $1 \mathrm{~b}$ that rotation of the $[\mathrm{Cu}(\mathrm{L})]$ unit near the $\mathrm{Cu}-\mathrm{N}$ bond produces an image occupying essentially the same molecular volume, providing a low barrier to disorder. The ratio of disordered components is $73: 27$ and is the same in both units. Coordination in the $d_{x^{2}-y^{2}}$ plane is completed by dimerisation with a symmetry-generated unit through the oxygen atoms of the aminophenol moiety of $\mathrm{L}^{2-}\left(\mathrm{O}_{\mathrm{ap}}\right)$ to give square $\mathrm{Cu}-\left(\mathrm{O}_{\mathrm{ap}}\right)_{2}-\mathrm{Cu}$ cores. The resultant $[\mathrm{Cu}(\mathrm{L})]_{2}$ units then are linked through long $\mathrm{Cu} \cdots \mathrm{O}$ bonds in the $d_{z^{2}}$ axis of the $\mathrm{Cu}$ ions to the salicylidene oxygen atoms $\left(\mathrm{O}_{\text {sal }}\right)$ to form similar $\mathrm{Cu}-\left(\mathrm{O}_{\text {sal }}\right)_{2}-\mathrm{Cu}$ linkages, extending the structure from a dimer to a one-dimensional coordination polymer chain in the $a$-axis with an inter-dimer distance of $3.18 \AA$ for the Cu1 chain and $3.22 \AA$ for the Cu2 chain (Figure 1c). The chains then close pack through van der Waal's interactions to form the 3D structure of 1 . The rapid precipitation of 1 from most solvents and the considerable crystallographic disorder have contributed to the structure being unknown until this study.
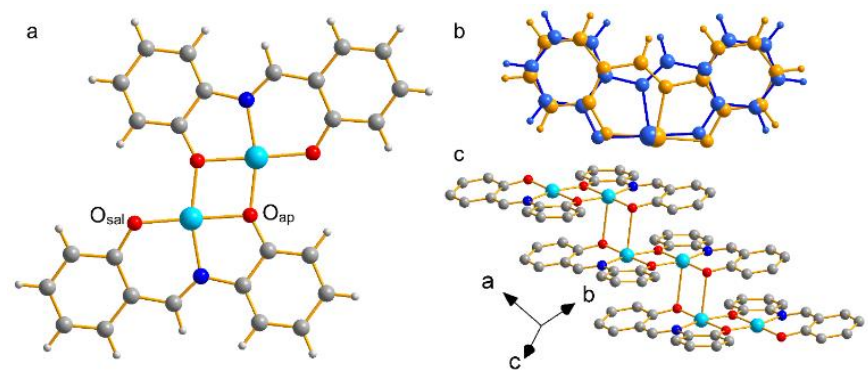

Figure 1 a) Dimerisation of the [Cu(L)] units in $\mathbf{1}$ (major component of $\mathrm{Cu} 1$ chain only). $\mathrm{O}_{\text {ap }}$ is the 2-aminophenol moiety and $\mathrm{O}_{\text {sal }}$ is the salicylidene moiety; b) full molecule disorder in the $[\mathrm{Cu}(\mathrm{L})]$ unit of $\mathbf{1}$ and $\left.\mathrm{c}\right)$ stacking of $[\mathrm{Cu}(\mathrm{L})]_{2}$ dimers in the $a$-axis.

\section{Polypyridyl complexes, $[\mathrm{Cu}(\mathrm{L})]_{2}(\mathrm{P})$}

The addition of a competing bridging ligand was able to disrupt the formation of 1. For example, when 4,4'-bipyridine (4,4'-bipy) was added to a DMSO solution of $\mathbf{1}$ and allowed to stand overnight dark brown plate-like crystals were formed. The resultant structure, $\left\{[\mathrm{Cu}(\mathrm{L})]_{2}\left(4,4^{\prime}-\text {-bipy }\right)\right\}_{n}(2)$ consists of a pair of $[\mathrm{Cu}(\mathrm{L})]$ units bridged by a 4,4'-bipy ligand (Figure 2) with a $\mathrm{Cu} \cdots \mathrm{Cu}$ distance of 11.086(7) $\AA$. Surprisingly, the long axial linkages between $[\mathrm{Cu}(\mathrm{L})]$ units were retained while the dimerisation through $\mathrm{O}_{a p}$ was prevented. The axial linkages between the $\left\{[\mathrm{Cu}(\mathrm{L})]_{2}\left(4,4^{\prime}-\right.\right.$-bipy $\left.)\right\}$ units form a twodimensional coordination polymer with a brickwork motif (Figure 3). As with 1, substantial disorder was present in the $[\mathrm{Cu}(\mathrm{L})]$ unit while the 4,4'-bipy ligand remained ordered. This was complicated further by pseudomerohedral twinning ( $a$ and $c$ differ by $<0.1 \%$ and $\beta=119.564^{\circ}$ ). 
A minor impurity phase in the synthesis of 2 was found where the $[\mathrm{Cu}(\mathrm{L})]_{2}\left(4,4^{\prime}\right.$-bipy) unit forms a discrete DMSO-solvated complex, $[\mathrm{Cu}(\mathrm{L})]_{2}\left(4,4^{\prime}\right.$-bipy).4DMSO (3). In 3, the axial $\mathrm{Cu}-\mathrm{O}$ bonds are absent, removing the $2 \mathrm{D}$ framework structure of 2 . While the core unit is the same, there is a far smaller torsion angle in the $4,4^{\prime}$-bipy $\left(0.5(5)^{\circ}\right)$ in $\mathbf{3}$ compared to $43.2(6)^{\circ}$ in $\mathbf{2}$. In both $\mathbf{2}$ and $\mathbf{3}$, the [Cu(L)] unit is coplanar with the pyridine coordinating to it. While $\mathbf{3}$ is essentially flat, the two ends of $\mathbf{2}$ are twisted relative to the torsion angle at the centre of the $4,4^{\prime}$-bipy.

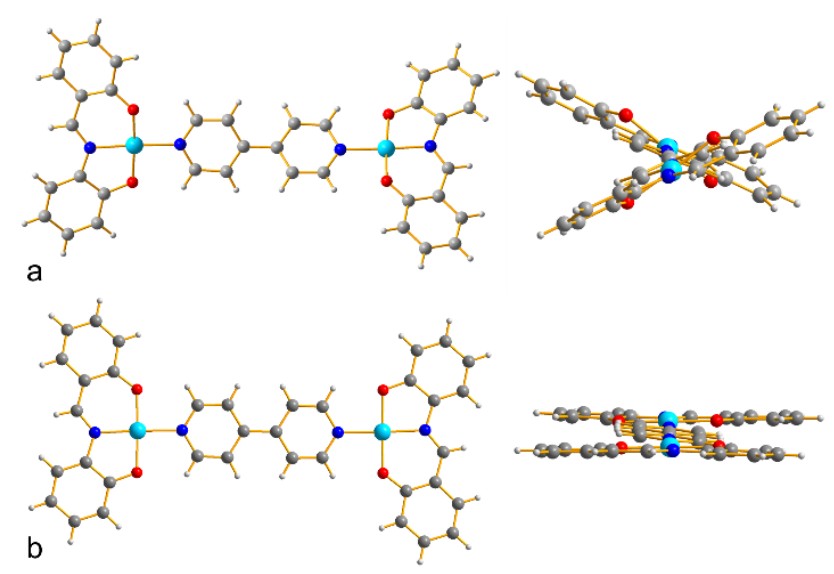

Figure 2: $[\mathrm{Cu}(\mathrm{L})]_{2}\left(4,4^{\prime}\right.$-bipy) units and end-on view of torsion angles in a) 2 and b) 3.

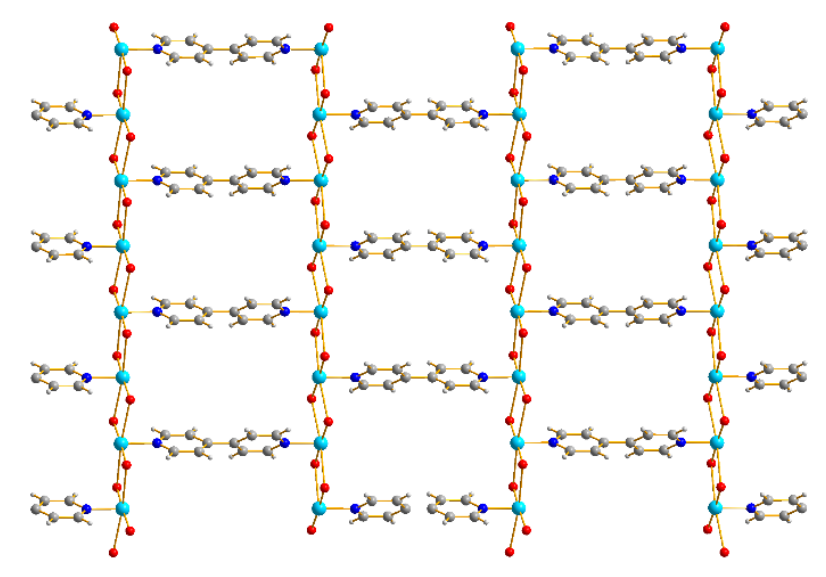

Figure 3: Brickwork layer motif in $\mathbf{2}$ displaying chains in the $b$-axis (majority of each $\mathbf{L}$ unit removed for clarity).

Having established the ability of $4,4^{\prime}$-bipy to bridge these units in both a coordination polymer and a discrete species, we investigated more complex bridging polypyridyls. Reaction of 4,4'bipyridylacetylene $\left(4,4^{\prime}\right.$-bpac) with a solution of 1 gives a discrete $[\mathrm{Cu}(\mathbf{L})]_{2}\left(4,4^{\prime}\right.$-bpac) complex (4, Figure 4) without the formation of a coordination polymer, similar to 3 and increases the $\mathrm{Cu} \cdots \mathrm{Cu}$ distance across the bridging ligand from $11.112(8) \AA$ in 3 to $13.701(5) \AA$. The $[\mathrm{Cu}(\mathrm{L})]_{2}\left(4,4^{\prime}\right.$-bpac) units pack by minimising the space in the material with no obvious hydrogen bonds, $\pi \cdots H$ or $\pi \cdots \pi$ interactions. Reaction of 1 with 4,4'-dithiodipyridine $\left(4,4^{\prime}\right.$-dtdp) produces $[\mathrm{Cu}(\mathrm{L})]_{2}\left(4,4^{\prime}\right.$-dtdp) (5, Figure 4b). The 4,4'-dtdp ligand takes a non-planar, non-linear conformation with a py-S-S-py torsion of $87.7(3)^{\circ}$ (average taken from the Cambridge Structural Database $\left.=87(4)^{\circ}\right)$. The $[\mathrm{Cu}(\mathrm{L})]_{2}\left(4,4^{\prime}\right.$-dtdp) units stack over the bend in the ligand in the $c$-axis (Figure $4 c$ ) and these stacks pack in the $a b$ plane to form the three-dimensional structure of $\mathbf{5}$. 

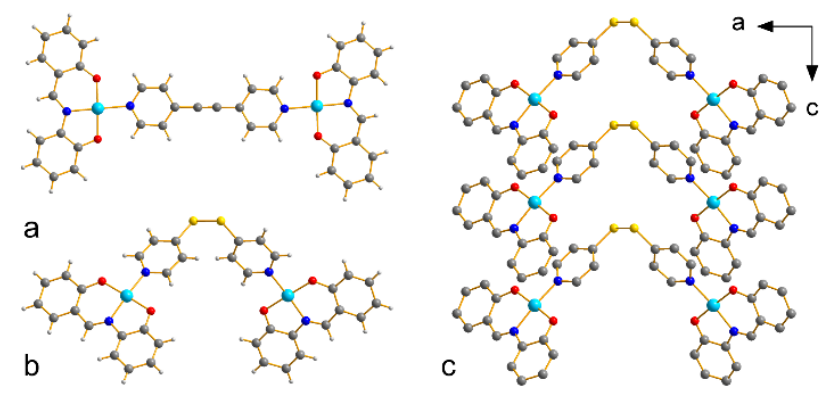

Figure 4 a) $[\mathrm{Cu}(\mathrm{L})]_{2}\left(4,4^{\prime}-\right.$-bpac) unit in $4 ;$ b) $[\mathrm{Cu}(\mathrm{L})]_{2}\left(4,4^{\prime}-\mathrm{dtdp}\right)$ unit in $\left.5 ; \mathrm{c}\right)$ stacking of $[\mathrm{Cu}(\mathrm{L})]_{2}\left(4,4^{\prime}\right.$-dtdp) units in $\mathbf{5}$, looking down the $b$-axis.

The reaction of 3,3'-bipyridylazine (3,3'-bpaz) and 4,4'-bipyridylazine $\left(4,4^{\prime}\right.$-bpaz) with $[\mathrm{Cu}(\mathrm{L})]$ also generated discrete complexes, $[\mathrm{Cu}(\mathbf{L})]_{2}\left(3,3^{\prime}\right.$-bpaz) $(\mathbf{6})$ and $[\mathrm{Cu}(\mathbf{L})]_{2}\left(4,4^{\prime}\right.$-bpaz) $(\mathbf{7})$ respectively. The $3,3^{\prime}$ bpaz ligand in 6 bridges the $[\mathrm{Cu}(\mathrm{L})]$ units in a flattened Z-shape (Figure $5 \mathrm{a}$ ) rather than adopting the conformation that would result in the widest separation of the $[\mathrm{Cu}(\mathrm{L})]$ units. Compound $\mathbf{7}$ (Figure $5 \mathrm{~b}$ ) displays disorder not only in the $\mathbf{L}$ group, but also in the 4,4'-bpaz ligand. The disorder in the [Cu(L)] unit is 64:36 and 85:15 in the 4,4'-bpaz ligand, indicating that either orientation of 4,4'-bpaz can bind to at least one of the $[\mathrm{Cu}(\mathrm{L})]$ orientations. Reaction of $3,3^{\prime}$-bipyridyloxamide $\left(3,3^{\prime}\right.$-bpox) with $[\mathrm{Cu}(\mathrm{L})]$ gives $\left\{[\mathrm{Cu}(\mathrm{L})]_{2}\left(3,3^{\prime} \text {-bpox) }\right\}_{n} .4 n D M S O(8)\right.$, which has a similar bridging mode to 6 (Figure $5 \mathrm{c}$ ). Dimerisation of $[\mathrm{Cu}(\mathrm{L})]$ units coupled with a further interaction with an oxygen of one of the amides produces a complex one-dimensional coordination polymer with a chain running in the $b$-axis (Figure 6). The chains pack to produce channels in the $b$-axis parallel to the chain that contain disordered DMSO solvent molecules. SQUEEZE ${ }^{47}$ analysis suggests three DMSO molecules per $[\mathrm{Cu}(\mathrm{L})]_{2}\left(3,3^{\prime}-\right.$-bpox $)$ unit in addition to the ordered DMSO molecule found in the structure solution. 4,4'-bipyridyloxamide $\left(4,4^{\prime}\right.$-bpox) and $[\mathrm{Cu}(\mathrm{L})]$ gives $[\mathrm{Cu}(\mathrm{L})(\mathrm{DMSO})]_{2}\left(4,4^{\prime}-\right.$-bpox) $(\mathbf{9})$, which has a similar $[\mathrm{Cu}(\mathrm{L})]_{2}(\mathbf{P})$ unit to 7 (Figure $5 \mathrm{~d}$ ) but with one DMSO molecule bound to each $\mathrm{Cu}$ ion, which hydrogen bonds to neighbouring $4,4^{\prime}$-bpox molecules to build the three-dimensional structure of the compound.

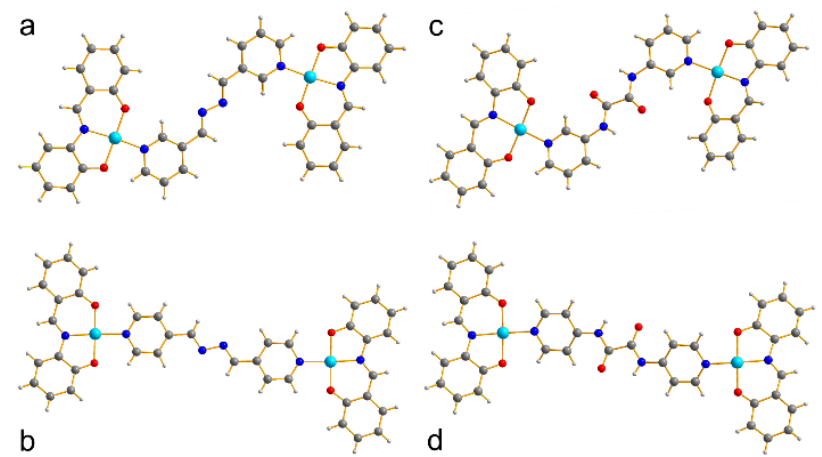

Figure $5[\mathrm{Cu}(\mathrm{L})]_{2}(\mathbf{P})$ units of a) compound $\left.\mathbf{6}\left(\mathbf{P}=3,3^{\prime}-\mathrm{bpaz}\right) ; \mathrm{b}\right)$ compound $\mathbf{7}\left(\mathbf{P}=4,4^{\prime}\right.$-bpaz $\left.) ; \mathrm{c}\right)$ compound $8(\mathbf{P}=$ 3,3'-bpox); d) compound $\mathbf{9}$ ( $\mathbf{P}=4,4^{\prime}$-bpox). 


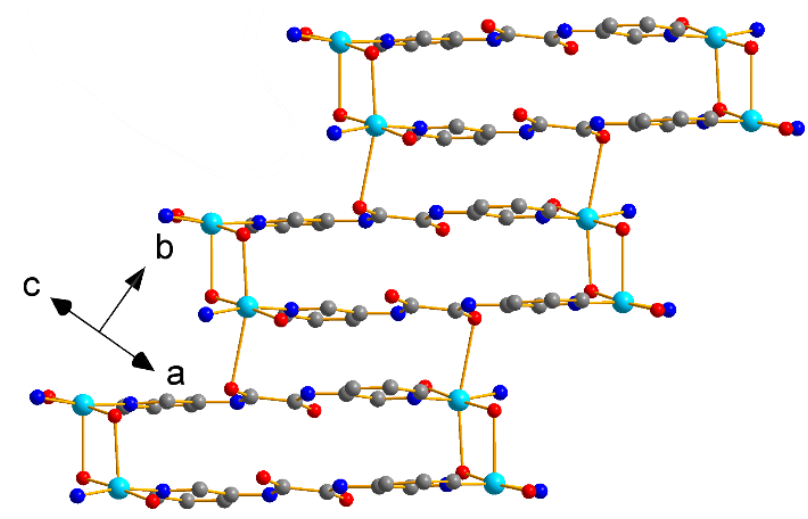

Figure 6 View of the chain structure in $\mathbf{8}$ looking down the 101 direction with L carbon atoms removed for clarity.
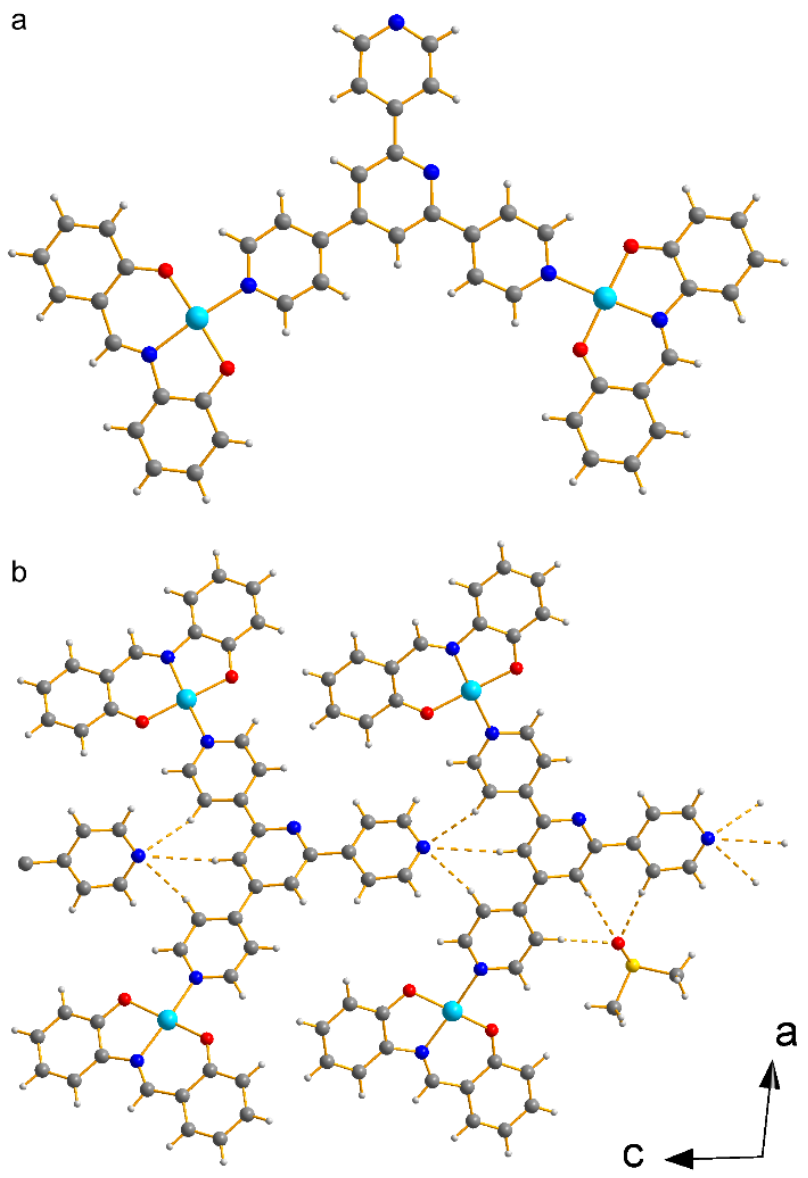

Figure 7 a) Bridging in $[\mathrm{Cu}(\mathrm{L})]_{2}\left(4,4^{\prime}, 4^{\prime \prime}\right.$-tppy)-DMSO (10); b) Packing of $[\mathrm{Cu}(\mathrm{L})]_{2}\left(4,4^{\prime}, 4^{\prime \prime}\right.$-tppy) units in 10, looking down the $b$-axis.

Having demonstrated the successful synthesis of $[\mathrm{Cu}(\mathrm{L})]_{2}(\mathbf{P})$ complexes with ditopic bridging pyridyl ligands, we investigated longer ligands and ligands with higher connectivities. Modifying the synthesis of $4^{\prime}$-(4-pyridyl)-2,2':6',2'--terpyridine, ${ }^{48,49}$ we obtained the tritopic ligand $4^{\prime}$-(4-pyridyl)-4, 2':6',4"terpyridine $\left(4,4^{\prime}, 4^{\prime \prime}\right.$-tppy) with which we synthesised $[\mathrm{Cu}(\mathrm{L})]_{2}\left(4,4^{\prime}, 4^{\prime \prime}\right.$-tppy).DMSO (10, Figure 7a). This tritopic ligand bridged two $[\mathrm{Cu}(\mathrm{L})]$ units, instead of the potential three. From synchrotron single-crystal X-ray diffraction data, the structure of $\mathbf{1 0}$ displays disorder in one of the [Cu(L)] units (74:26) with the disorder being too low to model in the other. The $4,4^{\prime}, 4^{\prime \prime}$-tppy ligand also appears to be ordered, despite the possibility for a three-fold rotational disorder in the plane of the ligand. A triple $\mathrm{C}-\mathrm{H} \cdots \mathrm{O}$ 
interaction with DMSO marks the position of one $\mathrm{C}-\mathrm{H}$ carbon in the central pyridine ring and the other takes part in a triple $\mathrm{C}-\mathrm{H} \cdots \mathrm{N}$ interaction. The complexes are held together by this last interaction with a neighbouring $4,4^{\prime}, 4^{\prime \prime}$-tppy to form one-dimensional chains in the $c$-axis (Figure $7 \mathrm{~b}$ ) with the chains packing to produce the three-dimensional structure.

The ligand 1,4-bis $\left(4,2^{\prime} ; 6^{\prime}, 4^{\prime \prime}\right.$-terpyridinyl)benzene $\left(4,4^{\prime}, 4^{\prime \prime}, 4^{\prime \prime \prime}\right.$-hxpb) has poor solubility in most solvents (except acetic and trifluoroacetic acid in which it readily dissolves) and precipitates quickly on cooling from hot DMSO, preventing formation of a complex. Ligand $N, N^{\prime}$-bis(4pyridyl)naphthalenediimide $\left(4,4^{\prime}\right.$-bpnd) is somewhat more soluble, but crystallised as the DMSO solvate of the ligand only (compound $\mathbf{1 1}$ - see ESI).

\section{Magnetic properties of 1 and 2}

Analysis of the structure of compound $\mathbf{1}$ indicates that the magnetic behaviour of the compound is likely to be dominated by the short-contact dimers. Bis- $\mu_{2}$-hydroxo/alkoxo bridged copper(II) dimers have couplings that are highly dependent on the $\mathrm{Cu}-\mathrm{O}-\mathrm{Cu}$ bridging angle, $\varphi$ (equation 1). ${ }^{50}$

$$
\begin{array}{lll}
J / k_{B}=(-74.53 \varphi+7270) / 0.695 \mathrm{~K} & \left(H=-J \sum S_{i} \cdot S_{j}\right) & \text { eq. } 1 \\
\chi=\frac{N g^{2} \mu_{B}^{2}}{k_{B} T} \cdot \frac{1}{3+\exp \left(-J / k_{B} T\right)} & \left(H=-J \sum S_{i} \cdot S_{j}\right) & \text { eq. 2 }
\end{array}
$$

The magnetic susceptibility plot for 1 (Figure 8a) shows a broad maximum centred around $270 \mathrm{~K}$ followed by a decreasing susceptibility on cooling with a rising tail under $50 \mathrm{~K}$. Modelling of the curve is considerably complicated by the presence of two chains, each with substantial disorder, giving a statistical mixture of major and minor component dimers in each chain. From the disordered model of 1 , it can be seen that in the dimers, there are a wide range of $\mathrm{Cu}-\mathrm{O}-\mathrm{Cu}$ bridging angles from strongly antiferromagnetic to strongly ferromagnetic. However, we can obtain an estimate of the average coupling in the major component chains from modelling the region 100-300 K with the BleaneyBowers model ${ }^{51}$ (equation 2) and ignoring the scale of the plot, giving $\mathrm{J} / \mathrm{k}_{B}=-427 \mathrm{~K}$. This value matches well with the calculated coupling of $-404 \mathrm{~K}$ for the average of all the $\mathrm{Cu}-\mathrm{O}-\mathrm{Cu}$ angles $\left(101.3^{\circ}\right)$. The EPR signal of 1 in the solid state at $330 \mathrm{~K}$ (Figure S19, ESI) is essentially flat apart from a very small peak (likely from the impurity tail seen in the susceptibility plot of $\mathbf{1}$ ), indicating a strong dominant antiferromagnetic coupling, as measured and predicted. 


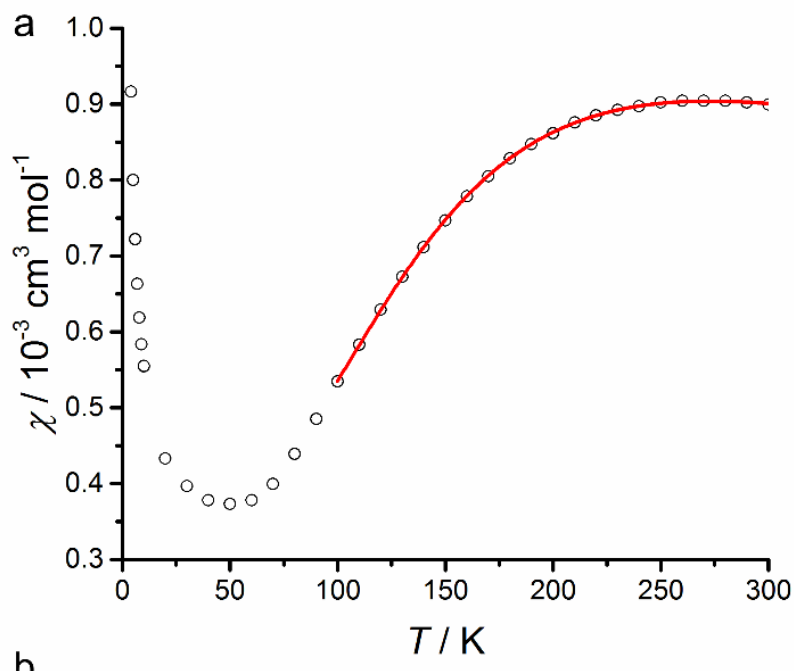

b

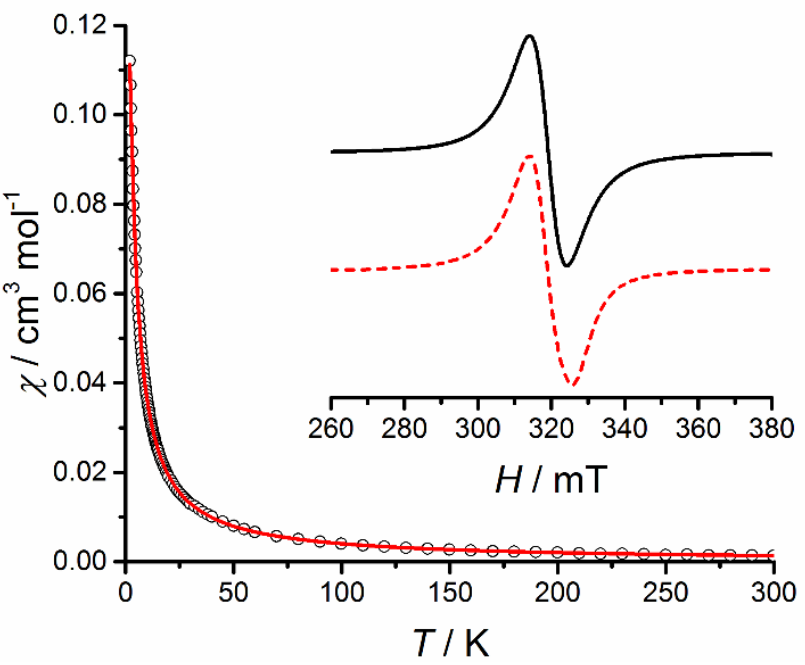

Figure 8 a) Magnetic susceptibility of 1 with fit for a single $S=1 / 2$ dimer model with $J / k_{B}=-427 \mathrm{~K}$ and b) Magnetic susceptibility of 2 with fit from $S=1 / 2$ antiferromagnetic chain model with $g=2.088$ and $J / k_{B}=-2.02 \mathrm{~K}$. Inset: EPR spectrum of 1 (solid line) with simulation (dashed line) $g=2.10$ and $J / k_{B}=-1.95 \mathrm{~K}$.

The magnetic susceptibility of compound $\mathbf{2}$ (Figure $8 \mathrm{~b}$ ) shows an increase on cooling from $300 \mathrm{~K}$ without displaying a maximum above $2 \mathrm{~K}$. The $\chi T(T)$ plot (Figure S21, ESI) shows a constant value on cooling from $300 \mathrm{~K}$ of $0.403(2) \mathrm{cm}^{3} \mathrm{Kmol}^{-1}$ with a decrease in value below $34 \mathrm{~K}$. A Curie-Weiss fit to the data gives $C=0.403(1) \mathrm{cm}^{3} \mathrm{Kmol}^{-1}$ and $\theta=-0.4(3) \mathrm{K}$. From the Curie constant and the value of $\chi T>45$ $\mathrm{K}$, we can derive a $g$-value of 2.07 . The Weiss constant is small, but indicates a dominant antiferromagnetic interaction. The structure of $\mathbf{2}$ consists of $\mathrm{Cu}-\left(\mathrm{O}_{2}\right)-\mathrm{Cu}$ chains connected through the magnetically-inactive $d_{z^{2}}$ orbital and contains two distinct linkages, not including any interaction across the 4,4'-bipyridine (which would be considerably weaker ${ }^{52}$ ). As an approximation, the two linkages were treated as equal and the Feyerherm ${ }^{53}$ polynomial (equation 3) for a uniform antiferromagnetic $S=1 / 2$ chain applied:

$\chi=\frac{N g^{2} \mu_{B}^{2}}{4 k_{B} T} \cdot \frac{1+0.08516 a+0.23351 a^{2}}{1+0.73382 a+0.13696 a^{2}+0.53568 a^{3}} \quad\left(H=-J \sum S_{i} \cdot S_{j}\right)$

where $a=|J| / k_{B} T$. 
We obtained $g=2.088(1)$ and $J / k_{B}=-2.02(1) \mathrm{K}$, consistent with the observations from the Curie-Weiss fit and the $\chi T(T)$ plot. The EPR spectrum of 2 (Figure $8 \mathrm{~b}$ inset) shows a single signal. $\mathrm{PHI}^{54}$ was used to simulate the EPR data of $\mathbf{2}$ from the crystal structure and resulted in a fit with $g=2.10$ and $J / k_{B}=-1.95$ $\mathrm{K}$, presenting a good agreement with the magnetic susceptibility modelling.

The modulation of the subunit linkage substantially modifies the magnetic interaction between the $\mathrm{Cu}$ (II) centres through directing the orientation of the magnetically-active $d_{x^{2}-y^{2}}$ orbital (Figure 9).

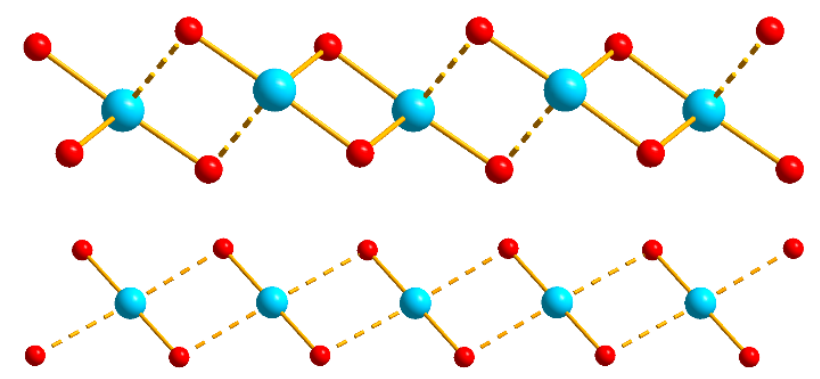

Figure 9 Structural comparison of the bis- $\mu_{2}$-phenoxo bridged copper(II) in $\mathbf{1}$ (top, $J / k_{B}=-427 \mathrm{~K}$ ) and $\mathbf{2}$ (bottom, $\left.J / k_{B}=-2.02 \mathrm{~K}\right)$. Dashed bonds represent linkages in the Jahn-Teller axis.

Compound 1 has a distinct structural similarity to $[\mathrm{Cu}(\mathrm{dsap})]_{2}{ }^{55}$ (dsap $=2-(3,5-$ dichlorosalicylidene)aminophenol)) where the addition of two $\mathrm{Cl}$ atoms to the salicyl ring resolves the disorder seen in $\mathbf{1}$. The magnetic couplings between the two compounds are very similar with $\mathrm{J} / \mathrm{k}_{B}=$ $-432 \mathrm{~K}$ for $[\mathrm{Cu}(\mathrm{dsap})]_{2}$, providing good agreement with Hatfield's model prediction of $-398 \mathrm{~K}$ for a $101.26^{\circ} \mathrm{Cu}-\mathrm{O}-\mathrm{Cu}$ angle. The coupling for 1 also matches well with a report on the magnetic properties of a range of substituted $\mathbf{L}$ ligands, ${ }^{46}$ although these lack any structural characterisation. The coupling in $\mathbf{2}$ is similar to that found in compounds with the same interaction pathway, such as $\mathrm{Na}_{2}\left[\mathrm{Cu}\left(\mathrm{C}_{2} \mathrm{O}_{4}\right)_{2}\right] \cdot 2 \mathrm{H}_{2} \mathrm{O}^{56}\left(\mathrm{~J} / \mathrm{k}_{\mathrm{B}}=-1.73 \mathrm{~K}\right)$. The magnetic susceptibility of 3-10 was not recorded due to the excessive distance between $\mathrm{Cu}$ centres across the polypyridyl ligands, minimising any magnetic coupling.

\section{Solution properties of 1}

Compound 1 has a room-temperature solubility of $11.4 \mathrm{mg} / \mathrm{ml}(21.3 \mathrm{mM})$ in neat DMSO (see SI) and UV-Vis spectroscopy (Figure 10) of a $10^{-5} \mathrm{M}$ solution of 1 in DMSO with $5 \% \mathrm{NEt}_{3}$ indicates that a [Cu(L)] complex exists in solution with a strong absorbance centred at $434 \mathrm{~nm}$ when compared to the spectra of $\mathrm{H}_{2} \mathrm{~L}$ and $\mathrm{CuCl}_{2} \cdot 2 \mathrm{H}_{2} \mathrm{O}$. The intense peak for the deprotonated Schiff base $L$ at $288 \mathrm{~nm}$ is not present in the spectrum of $\mathbf{1}$, indicating that the $[\mathrm{Cu}(\mathrm{L})]$ unit is very stable to dissociation. It is likely that a solvated $[\mathrm{Cu}(\mathrm{L})]$ unit is present, but whether this occurs as a monomer or dimer is unclear from the UV-vis data. Mass spectrometry would appear an ideal method to identify the solution-phase species present, but precipitation of 1 from DMSO on addition of other solvents and the non-volatility of the phase preclude standard MS techniques. To establish the identity of the solution species, we investigated the EPR spectra of solutions of 1 : if the $[\mathrm{Cu}(\mathrm{L})]_{2}$ dimer is present as the dominant solution species, the solution would be effectively EPR-silent due to the strong antiferromagnetic coupling and dilution, but if the dimer is dissociated by the solvent, then a clear signal would result. 


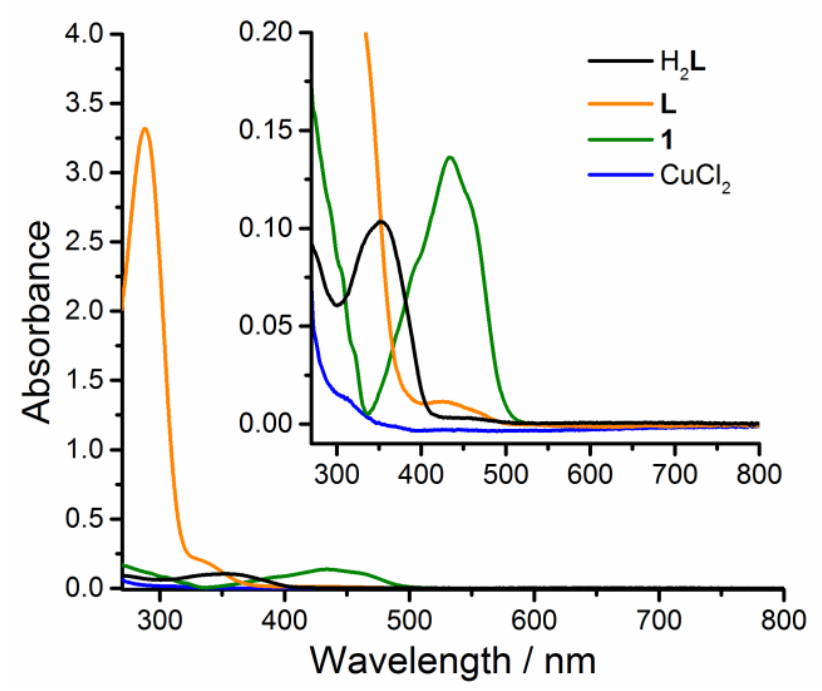

Figure $10 \mathrm{UV}$-vis spectroscopy of $1 \times 10^{-5} \mathrm{M}$ solutions of a) $\mathrm{H}_{2} \mathrm{~L}$ in DMSO (black); b) L $\mathrm{L}^{2-}$ in $5 \% \mathrm{NEt}_{3}$ in DMSO (orange); c) compound $\mathbf{1}$ in $5 \% \mathrm{NEt}_{3}$ in $\mathrm{DMSO}$ (green) and d) $\mathrm{CuCl}_{2} \cdot 2 \mathrm{H}_{2} \mathrm{O}$ in $5 \% \mathrm{NEt}_{3}$ in DMSO (blue).

There are four peaks in the EPR spectrum (Figure 11, left) with $g=2.18,2.12,2.07$ and 2.03. The 2.18 peak corresponds to the DMSO-solvated $\mathrm{Cu}(\mathrm{II})$ ion, ${ }^{57,58}$ leaving three peaks. Deconvolution of the integrated spectrum reveals a ratio of 38:21:41 of the three peaks. Similarly, deconvolution of the UVvis spectrum (Figure 11, right) reveals three peaks with a ratio of 33:19:48, closely matching the EPR data. This would indicate there are different solvation states of the $[\mathrm{Cu}(\mathrm{L})]$ monomer species in DMSO solution, likely forming $[\mathrm{Cu}(\mathrm{L})](\mathrm{DMSO})_{n}$ where $n=1,2$ or 3 , consistent with completing the square planar coordination sphere of the $\mathrm{Cu}(\mathrm{II})$ ion and variable solvation of the Jahn-Teller axis. The ratio of solvated species does not appear to be affected by concentration - a difference plot made from the EPR signal of a scaled $2 \times 10^{-3} \mathrm{M}$ plot subtracted from the $1 \times 10^{-2} \mathrm{M}$ plot revealed no difference peaks (figure S22, ESI).
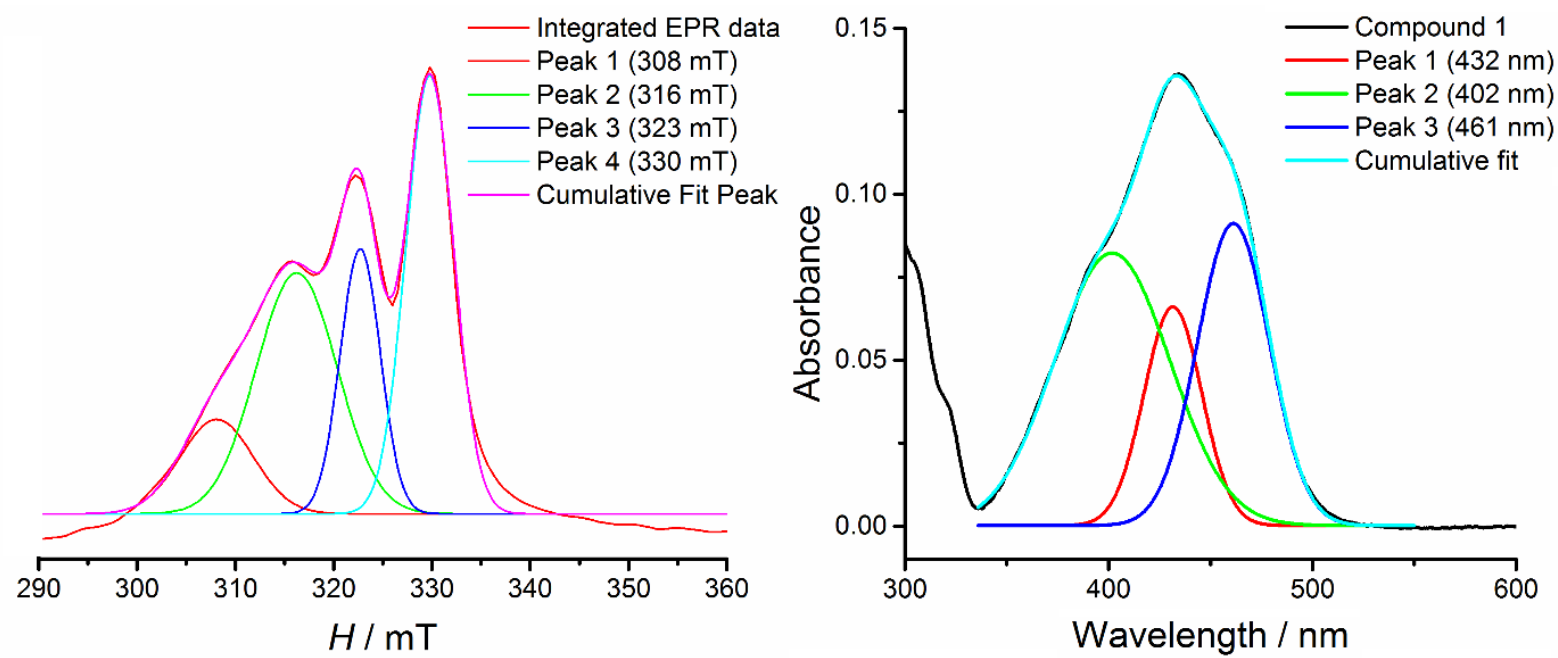

Figure 11 left: Integrated and deconvoluted EPR data for a $1 \times 10^{-2} \mathrm{M}$ solution of 1 in DMSO at $293 \mathrm{~K}$ (peak 1 is from a DMSO-solvated free Cu(II) ion); right: Deconvoluted UV-vis data for a $1 \times 10^{-5} \mathrm{M}$ solution of 1 in DMSO.

The EPR spectrum of a reaction mixture for the synthesis of $\mathbf{2}$ revealed a difference in the position of the peaks, indicating that complexation of the $[\mathrm{Cu}(\mathrm{L})]$ units and 4,4'-bipy is occurring in solution before crystallisation (figure 12). 


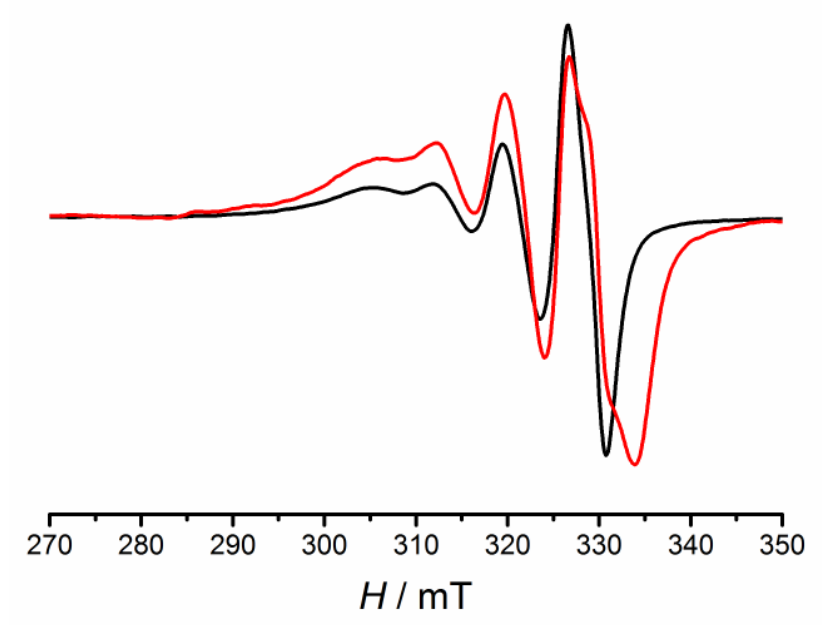

Figure 12 Comparison of EPR spectra of a $1 \times 10^{-2} \mathrm{M}$ solution of $\mathbf{1}$ (black line) and $\mathbf{2}$ (red line) in DMSO at $293 \mathrm{~K}$.

\section{Discussion}

The solubility of 1 and the identification of the solution species in DMSO by a novel combination of UV-vis/EPR has allowed us to rationally design new complexes by bridging the monomeric $[\mathrm{Cu}(\mathrm{L})]$ units with a range polypyridyl ligands containing a number of functional groups (e.g. amide, disulfide, acetylene). The diffusion of water vapour from the air into the DMSO solution allows for the slow growth of crystals suitable for structural analysis. The limiting factor in the formation of complexes appears to be ligand solubility. Ligand $4,4^{\prime}, 4^{\prime \prime}, 4^{\prime \prime \prime}-\mathrm{hxpb}$ is sparingly soluble in hot DMSO: at $170^{\circ} \mathrm{C}, 10.1$ $\mathrm{mg}$ can dissolve in $25 \mathrm{ml}$ DMSO and rapidly precipitates on cooling to room temperature, even after dilution to $250 \mathrm{ml}$. Ligand 4,4'-bpnd has a lower solubility than 1 of $6.2 \mathrm{mg} / \mathrm{ml}(14.7 \mathrm{mM})$ in DMSO at room temperature and it crystallises from the reaction mixture before producing a complex to give a DMSO solvate structure (11 - see SI). In both cases, absorption of water into the DMSO causes precipitation of the ligand and compound $\mathbf{1}$ follows after standing for several days. The relative insolubility of these two ligands compared to that of 1 allows us to place some constraints on the applicability of using polypyridine ligands to form $[\mathrm{Cu}(\mathbf{L})]_{2}(\mathbf{P})$ complexes. It has been previously shown that appending alkoxy groups to the central benzene core of $4,4^{\prime}, 4^{\prime \prime}, 4^{\prime \prime \prime}$-hxpb ${ }^{59}$ or nitriles to the peripheral pyridine moieties ${ }^{60}$ can increase the solubility of the ligand so that coordination complexes can be formed.

Structurally, the ability of the $[\mathrm{Cu}(\mathrm{L})]$ group to rotate around an axis just off the $\mathrm{Cu}-\mathrm{N}$ bond made the structure solution of this series of compounds somewhat challenging, especially when coupled with disorder in the pyridine ligand resulting in full-molecule disorder. The value of $[\mathrm{Cu}(\mathrm{L})]$ disorder ranges from 50:50 to 89:11 (5 and 3, 4,4'-dtdp and 4,4'-bipy). This disorder likely arises from the similar molecular volume of the superposition of the two orientations, as illustrated in Figure 1. Several related ligands with additional groups on either the salicylidene or 2-aminophenol rings see this resolved with a lack of disorder. ${ }^{55,61,62}$

The polypyridyl-containing complexes are stable to air, water, methanol and acetone, except compound 8, which shows degradation on attempts to remove DMSO from the pores, resulting in a new crystalline phase that we have not been able to structurally characterise. The difficulties in removing DMSO in several cases make it somewhat difficult to obtain reliable elemental analysis data for several of these compounds. Compounds $\mathbf{8}$ and $\mathbf{1 0}$ show a small residual DMSO content by elemental analysis.

\section{Conclusions}


The solution behaviour of compound $\mathbf{1}$ in forming a stable [Cu(L)] unit in DMSO (as identified by the novel combined UV-vis/EPR experiment) is unusual and presents a novel strategy of utilising poorly soluble coordination polymers as source of supramolecular building units for the formation of new coordination compounds. The ability of bridging polypyridyl ligands to link the $[\mathrm{Cu}(\mathrm{L})]$ units in the resultant complexes allows us to fundamentally alter the connectivity from zero- to two-dimensional. The constraints placed by the solubility of the polypyridyl bridging ligands enable us to make predictions as to the success of complex formation so that specific complexes can be planned with a high degree of confidence. Further work into the design of soluble polypyridyls with multiple connectivity modes is being investigated to lead towards three-dimensional materials such as MOFs. The presence of a paramagnetic metal ion coupled with the ability to change connectivity allows us to substantially modify the magnetic properties of these materials. The addition of 4,4'-bipy to a solution of 1 markedly changes the strength of antiferromagnetic interaction through the $\mathrm{Cu}-(\mathrm{O})_{2}-\mathrm{Cu}$ linkages by reorientation of the magnetically-active $d_{x^{2}-y^{2}}$ orbital, a useful tool in the design of desirable magnetic interactions.

This work has laid the foundations for the rational design of both structure and magnetic properties from this type of Schiff base. Further work is planned for the inclusion of other paramagnetic ions into complexes with $\mathrm{H}_{2} \mathbf{L}$ to widen the range of structures and magnetic interactions.

\section{Experimental}

\section{Experimental methods}

Reagents were obtained from commercial suppliers and used without further purification. Single crystal X-ray diffraction data were collected at $100 \mathrm{~K}$ on a Rigaku AFC12 goniometer equipped with an enhanced sensitivity (HG) Saturn 724+ detector mounted at the window of an FR-E+ Superbright Mo$K_{\alpha}$ rotating anode generator $(\lambda=0.71075 \AA)$ with $\operatorname{VHF}(\mathbf{1}$ and $\mathbf{8})$ or $\operatorname{HF}(\mathbf{2}-\mathbf{7}, \mathbf{9}, \mathbf{1 1})$ varimax optics ${ }^{63}$ apart from 10 which was collected on beamline $I 19$ at Diamond $(\lambda=0.6889 \AA)$. Unit cell parameters were refined against all data and an empirical absorption correction applied in CrysalisPro ${ }^{64}$ for $(\mathbf{1}, \mathbf{2}, \mathbf{4 - 1 1})$ or CrystalClear $3.1 \mathrm{~b} 27^{65}$ (3). All structures were solved by direct methods using Superflip ${ }^{66-68}(\mathbf{1}, \mathbf{3 - 1 1})$ or SHELXT ${ }^{69}(2)$ and refined on $F_{O}{ }^{2}$ by SHELXL-2013 ${ }^{70}$ in OLEX2 v1.2. ${ }^{71}$ All hydrogen atoms were added in calculated positions and refined in riding mode on the parent atom. Data deposited with the CSD (CSD-1528695-1528704 1-10, CSD-1528735 11). Powder X-ray diffraction was carried out using a Bruker D2 Phaser with a Lynxeye detector and $\mathrm{Cu}-\mathrm{K}_{\alpha}$ radiation (1.5405 $\AA$ ). Le Bail profile fits on powder $X$-ray data were performed in Rietica ${ }^{72}$ to ensure phase identity and sample purity.

$X$-band EPR spectra were recorded on a Magnetech Miniscope 200 equipped with frequency counter. Samples were loaded into $50 \mu \mathrm{l}$ glass capillaries and data collected at $293 \mathrm{~K}$, except 1 in the solid state, which was collected at $330 \mathrm{~K}$. Background subtractions were performed using a DMSO-filled capillary for solutions and an empty capillary for solids. Magnetic susceptibility measurements for $\mathbf{1}$ were carried out on a Quantum Design MPMS XL-5 magnetometer from 2-300 K under an applied field of 10,000 G. Measurements for 2 were carried out on a Quantum Design PPMS with VSM magnetometer option from 2-300 K under an applied field of 2,000 G. Diamagnetic corrections were calculated from the approximation $-0.45 \times$ formula mass $\times 10^{-6} \mathrm{~cm}^{3} \mathrm{~mol}^{-1}$. Data for 2 was then subsequently corrected for a zero-field offset to produce a linear plot above $200 \mathrm{~K}$.

NMR spectra of ligands were recorded on a Bruker DPX400 NMR spectrometer at $300 \mathrm{~K}$ except $4,4^{\prime}, 4^{\prime \prime}, 4^{\prime \prime \prime}$-hxpb which was recorded on a Varian NMR System $500 \mathrm{MHz}$ spectrometer at $300 \mathrm{~K}$. Chemical shifts are reported in parts per million and referenced to residual protonated solvent $\left(\mathrm{CDCl}_{3}\right.$, DMSO- $d_{6}$ or TFA).

Elemental analysis was performed on an Exeter Analytical CE 440 elemental analyser.

Synthesis of $\left\{[\mathrm{Cu}(\mathrm{L})]_{2}\right\}_{\mathrm{n}}(1)$ 
$\mathrm{H}_{2}(\mathrm{~L})(832 \mathrm{mg}, 4.00 \mathrm{mmol})$ was stirred in $70 \mathrm{ml} \mathrm{EtOH}$ at $75^{\circ} \mathrm{C}$ and $\mathrm{NEt}_{3}$ added $(1 \mathrm{ml})$. A solution of $\mathrm{CuCl}_{2} \cdot 2 \mathrm{H}_{2} \mathrm{O}(680 \mathrm{mg}, 4.00 \mathrm{mmol})$ in $40 \mathrm{ml} \mathrm{EtOH}$ was added dropwise with stirring. The resultant fine green precipitate of $\left\{[\mathrm{Cu}(\mathrm{L})]_{2}\right\}_{n}(\mathbf{1})$ was filtered, washed with $20 \mathrm{ml} \mathrm{EtOH}$ and left to dry overnight. Yield $832 \mathrm{mg}$ (76\%). Single crystals of 1 were formed by dissolving 1 ( $27.5 \mathrm{mg}, 0.1 \mathrm{mmol})$ from the above powder synthesis in $3 \mathrm{ml}$ DMSO and leaving open in air to crystallise over six days.

\section{Example synthesis of $[\mathrm{Cu}(\mathrm{L})]_{\mathrm{n}}(\mathrm{P})$ complexes: $[\mathrm{Cu}(\mathrm{L})]_{2}\left(4,4^{\prime}-\right.$-bpac $)(4)$}

$\left\{[\mathrm{Cu}(\mathrm{L})]_{2}\right\}_{n}(27.5 \mathrm{mg}, 0.05 \mathrm{mmol})$ and 4,4'-bpac $(18.0 \mathrm{mg}, 0.1 \mathrm{mmol})$ were dissolved in $7 \mathrm{ml}$ DMSO on a hotplate set to $170{ }^{\circ} \mathrm{C}$ and left to cool in air. After three days, greenish-black single crystals of $[\mathrm{Cu}(\mathrm{L})]_{2}\left(4,4^{\prime}-\mathrm{bpac}\right)(4)$ had formed which were filtered and washed with $2 \times 2 \mathrm{ml}$ 9:1 DMSO: $\mathrm{H}_{2} \mathrm{O}$ and 2 $\times 2 \mathrm{ml}$ acetone. Yield $14 \mathrm{mg}(38 \%)$.

Full experimental details are given for all compounds in the ESI.

\section{Acknowledgements}

We would like to thank Dr Mark Light (University of Southampton) for his assistance with processing the original SCXRD data for 2, Dr Yannick Ortin (UCD) for assistance with NMR measurements and interpretation, Mr Andrew Barker for assistance with EPR measurements and Dr Deanna D'Alessandro (University of Sydney) for advice on the UV-vis and EPR interpretation. We are also grateful to Professor Cameron J. Kepert (University of Sydney) for provision of access to a Physical Property Measurement System for magnetic susceptibility measurements.

\section{Associated Content}

Supporting Information

Detailed synthetic procedures and characterisation for ligands and complexes; crystal structure data and descriptions.

\section{Author Information \\ Corresponding author \\ *Email: tony.keene@ucd.ie \\ Funding}

This research was supported by a Marie Curie International Incoming Fellowship (TDK) within the 7th European Community Framework Program (grant PIIF-GA-2011-300462) and by a Worldwide Universities Network Global Partnership Fund award. GGM and AJF acknowledge the support of SFI via an Investigator Project Award (12/IP/1703), and additional funding to AJF from the National University of Ireland, University College Dublin and the Cultural Service of the French Embassy in Ireland.

\section{References}

(1) Tranchemontagne, D. J.; Mendoza-Cortés, J. L.; O’Keeffe, M.; Yaghi, O. M. Secondary Building Units, Nets and Bonding in the Chemistry of Metal-Organic Frameworks. Chem. Soc. Rev. 2009, 
38 (5), 1257-1283 DOI: 10.1039/b817735j.

(2) Metal-Organic Frameworks: Applications from Catalysis to Gas Storage, First Edit.; Farrusseng, D., Ed.; Wiley-VCH Verlag GmbH \& Co. KGaA, 2011.

(3) Yaghi, O. M.; M, O. K.; Ockwig, N. W.; Chae, H. K.; Eddaoudi, M.; Kim, J. Reticular Synthesis and the Design of New Materials. Nature 2003, 423 (6941), 705-714 DOI: 10.1038/nature01650.

(4) Tranchemontagne, D. J.; Ni, Z.; O'Keeffe, M.; Yaghi, O. M. Reticular Chemistry of Metal-Organic Polyhedra. Angew. Chem. Int. Ed. 2008, 47 (28), 5136-5147 DOI: 10.1002/anie.200705008.

(5) Vardhan, H.; Yusubov, M.; Verpoort, F. Self-Assembled Metal-organic Polyhedra: An Overview of Various Applications. Coord. Chem. Rev. 2016, 306 (P1), 171-194 DOI: 10.1016/j.ccr.2015.05.016.

(6) Farha, O. K.; Hupp, J. T. Rational Design, Synthesis, Purification, and Activation of Metal-Organic Framework Materials. Acc. Chem. Res. 2010, 43 (8), 1166-1175 DOI: 10.1021/ar1000617.

(7) Steel, P. J. Ligand Design in Multimetallic Architectures: Six Lessons Learned. Acc. Chem. Res. 2005, 38 (4), 243-250 DOI: 10.1021/ar040166v.

(8) Biradha, K.; Sarkar, M.; Rajput, L. Crystal Engineering of Coordination Polymers Using 4,4'bipyridine as a Bond between Transition Metal Atoms. Chem. Commun. 2006, 4169-4179 DOI: 10.1039/b606184b.

(9) Zhang, J.-W.; Kan, X.-M.; Li, X.-L.; Luan, J.; Wang, X.-L. Transition Metal Carboxylate Coordination Polymers with Amide-Bridged Polypyridine Co-Ligands: Assemblies and Properties. CrystEngComm 2015, 17 (21), 3887-3907 DOI: 10.1039/C4CE02531H.

(10) Janiak, C.; Vieth, J. K. MOFs, MILs and More: Concepts, Properties and Applications for Porous Coordination Networks (PCNs). New J. Chem. 2010, 34 (11), 2366 DOI: 10.1039/c0nj00275e.

(11) Keene, T. D.; Murphy, M. J.; Price, J. R.; Sciortino, N. F.; Southon, P. D.; Kepert, C. J. Multifunctional MOFs through $\mathrm{CO}_{2}$ Fixation: A Metamagnetic Kagome Lattice with Uniaxial Zero Thermal Expansion and Reversible Guest Sorption. Dalton Trans. 2014, 43 (39), 1476614771 DOI: 10.1039/c4dt02205j.

(12) Keene, T. D.; Murphy, M. J.; Price, J. R.; Price, D. J.; Kepert, C. J. A New Modification of an Old Framework: Hofmann Layers with Unusual Tetracyanidometallate Groups. Dalton Trans. 2011, 40 (43), 11621 DOI: 10.1039/c1dt11183c.

(13) Ohtani, R.; Kitagawa, S.; Ohba, M. Coordination Pillared Layers Using a Dinuclear Mn(V) Complex as a Secondary Building Unit. Polyhedron 2013, 52, 591-597 DOI: 10.1016/j.poly.2012.08.006.

(14) Clements, J. E.; Price, J. R.; Neville, S. M.; Kepert, C. J. Perturbation of Spin Crossover Behavior by Covalent Post-Synthetic Modification of a Porous Metal-Organic Framework. Angew. Chem. Int. Ed. 2014, 53 (38), 10164-10168 DOI: 10.1002/anie.201402951.

(15) Clements, J. E.; Price, J. R.; Neville, S. M.; Kepert, C. J. Hysteretic Four-Step Spin Crossover within a Three-Dimensional Porous Hofmann-like Material. Angew. Chem. Int. Ed. 2016, 55 (48), 15105-15109 DOI: 10.1002/anie.201605418.

(16) Garcia, Y.; Niel, V.; Muñoz, M. C.; Real, J. A. Spin Crossover in 1D , 2D and 3D Polymeric Fe (II) Networks. Top. Curr. Chem. 2004, 233, 229-257 DOI: 10.1007/b95408.

(17) Sciortino, N. F.; Scherl-Gruenwald, K. R.; Chastanet, G.; Halder, G. J.; Chapman, K. W.; Létard, J. F.; Kepert, C. J. Hysteretic Three-Step Spin Crossover in a Thermo- and Photochromic 3D Pillared Hofmann-Type Metal-Organic Framework. Angew. Chem. Int. Ed. 2012, 51 (40), 1015410158 DOI: 10.1002/anie.201204387.

(18) Hernández-Molina, R.; Mederos, A. Acyclic and Macrocyclic Schiff Base Ligands. In Comprehensive Coordination Chemistry II; Elsevier, 2003; pp 411-446.

(19) Gupta, K. C.; Sutar, A. K. Catalytic Activities of Schiff Base Transition Metal Complexes. Coord. Chem. Rev. 2008, 252 (12-14), 1420-1450 DOI: 10.1016/j.ccr.2007.09.005.

(20) Cozzi, P. G. Metal-Salen Schiff Base Complexes in Catalysis: Practical Aspects. Chem. Soc. Rev. 2004, 33 (7), 410-421 DOI: 10.1039/B307853C. 
(21) Yamada, S. Advancement in Stereochemical Aspects of Schiff Base Metal Complexes. Coord. Chem. Rev. 1999, 190-192, 537-555 DOI: 10.1016/S0010-8545(99)00099-5.

(22) Sunatsuki, Y.; Motoda, Y.; Matsumoto, N. Copper(II) Complexes with Multidentate Schiff-Base Ligands Containing Imidazole Groups: Ligand-Complex or Self-Complementary Molecule? Coord. Chem. Rev. 2002, 226 (1-2), 199-209 DOI: 10.1016/S0010-8545(01)00417-9.

(23) Gallant, A. J.; MacLachlan, M. J. Ion-Induced Tubular Assembly of Conjugated Schiff-Base Macrocycles. Angew. Chem. Int. Ed. 2003, 42 (43), 5307-5310 DOI: 10.1002/anie.200352395.

(24) Miyasaka, H.; Clérac, R.; Wernsdorfer, W.; Lecren, L.; Bonhomme, C.; Sugiura, K.; Yamashita, M. A Dimeric Manganese(III) Tetradentate Schiff Base Complex as a Single-Molecule Magnet. Angew. Chem. Int. Ed. 2004, 43 (21), 2801-2805 DOI: 10.1002/anie.200353563.

(25) Naiya, S.; Wang, H.-S.; Drew, M. G. B.; Song, Y.; Ghosh, A. Structural and Magnetic Studies of Schiff Base Complexes of nickel(II) Nitrite: Change in Crystalline State, Ligand Rearrangement and a Very Rare $\mu$-Nitrito-1kO:2kN:3kO' Bridging Mode. Dalton Trans. 2011, 40 (12), 27442756 DOI: 10.1039/c0dt00978d.

(26) Bhattacharyya, A.; Ghosh, B. N.; Herrero, S.; Rissanen, K.; Jiménez-Aparicio, R.; Chattopadhyay, S. Formation of a Novel Ferromagnetic End-to-End Cyanate Bridged Homochiral Helical copper(II) Schiff Base Complex via Spontaneous Symmetry Breaking. Dalton Trans. 2015, 44 (2), 493-497 DOI: 10.1039/C4DT03166K.

(27) Kitaura, R.; Onoyama, G.; Sakamoto, H.; Matsuda, R.; Noro, S.; Kitagawa, S. Immobilization of a Metallo Schiff Base into a Microporous Coordination Polymer. Angew. Chem. Int. Ed. Engl. 2004, 43 (20), 2684-2687.

(28) Shultz, A. M.; Sarjeant, A. A.; Farha, O. K.; Hupp, J. T.; Nguyen, S. T. Post-Synthesis Modification of a Metal-Organic Framework To Form Metallosalen-Containing MOF Materials. J. Am. Chem. Soc. 2011, 133 (34), 13252-13255 DOI: 10.1021/ja204820d.

(29) Shultz, A. M.; Farha, O. K.; Adhikari, D.; Sarjeant, A. A.; Hupp, J. T.; Nguyen, S. T. Selective Surface and Near-Surface Modification of a Noncatenated, Catalytically Active Metal-Organic Framework Material Based on Mn(salen) Struts. Inorg. Chem. 2011, 50 (8), 3174-3176 DOI: 10.1021/ic101952y.

(30) Alexandropoulos, D. I.; Nguyen, T. N.; Cunha-Silva, L.; Zafiropoulos, T. F.; Escuer, A.; Christou, G.; Stamatatos, T. C. Slow Magnetization Relaxation in Unprecedented Mn"'4Dy"l'3 and Mn'"4Dy"'4 Clusters from the Use of N-Salicylidene-O-Aminophenol. Inorg. Chem. 2013, 52 (3), 1179-1181 DOI: 10.1021/ic302505p.

(31) Wang, H.; Ke, H.; Lin, S.-Y.; Guo, Y.; Zhao, L.; Tang, J.; Li, Y.-H. Heterometallic Octanuclear RE"'3Ni"5 (RE = Dy'", Gd'"' and Y'I') Clusters with Slow Magnetic Relaxation for the Dysprosium Derivative. Dalton Trans. 2013, 42 (15), 5298 DOI: 10.1039/c3dt32572e.

(32) Mukherjee, S.; Chaudhari, A. K.; Xue, S.; Tang, J.; Ghosh, S. K. An Asymmetrically Connected Hexanuclear Dylll ${ }_{6}$ Cluster Exhibiting Slow Magnetic Relaxation. Inorg. Chem. Commun. 2013, 35, 144-148 DOI: 10.1016/j.inoche.2013.06.027.

(33) Hartung, J.; Drees, S.; Greb, M.; Schmidt, P.; Svoboda, I.; Fuess, H.; Murso, A.; Stalke, D. (Schiffbase)vanadium(V) Complex-Catalyzed Oxidations of Substituted Bis(homoallylic) Alcohols Stereoselective Synthesis of Functionalized Tetrahydrofurans. Eur. J. Org. Chem. 2003, 2003 (13), 2388-2408 DOI: 10.1002/ejoc.200200644.

(34) Nakamura, T.; Kuranuki, E.; Niwa, K.; Fujiwara, M.; Matsushita, T. Preparation, Structures and Properties of Novel Mono- and Trinuclear Iron(III) Complexes with Mixed Ligands. Chem. Lett. 2000, 29 (3), 248-249 DOI: 10.1246/cl.2000.248.

(35) Huang, S.-H.; Jhan, S.-Y.; Yang, C.-I.; Tsai, H.-L. Synthesis, Structure, and Magnetic Properties of a Tetradecanuclear Manganese Complex. Polyhedron 2013, 66, 245-251 DOI: 10.1016/j.poly.2013.05.002.

(36) Xiang, J.; Jia, L.-H.; Man, W.-L.; Qian, K.; Lee, G.-H.; Peng, S.-M.; Yiu, S.-M.; Gao, S.; Lau, T.-C. A Novel triazidoruthenium(III) Building Block for the Construction of Polynuclear Compounds. Dalton Trans. 2012, 41 (19), 5794 DOI: 10.1039/c2dt11810f. 
(37) Salehi, M.; Rahimifar, F.; Kubicki, M.; Asadi, A. Structural, Spectroscopic, Electrochemical and Antibacterial Studies of Some New nickel(II) Schiff Base Complexes. Inorg. Chim. Acta 2016, 443, 28-35 DOI: 10.1016/j.ica.2015.12.016.

(38) Mondal, K. C.; Kostakis, G. E.; Lan, Y.; Wernsdorfer, W.; Anson, C. E.; Powell, A. K. DefectDicubane $\mathrm{Ni}_{2} \mathrm{Ln}_{2}(\mathrm{Ln}=\mathrm{Dy}, \mathrm{Tb})$ Single Molecule Magnets. Inorg. Chem. 2011, 50 (22), 1160411611 DOI: 10.1021/ic2015397.

(39) Ke, H.; Zhao, L.; Guo, Y.; Tang, J. Syntheses, Structures, and Magnetic Analyses of a Family of Heterometallic Hexanuclear $\left[\mathrm{Ni}_{4} \mathrm{M}_{2}\right](\mathrm{M}=\mathrm{Gd}, \mathrm{Dy}, \mathrm{Y})$ Compounds: Observation of Slow Magnetic Relaxation in the Dy III Derivative. Inorg. Chem. 2012, 51 (4), 2699-2705 DOI: 10.1021/ic202699k.

(40) Mondal, K. C.; Kostakis, G. E.; Lan, Y.; Powell, A. K. Magnetic Properties of Five Planar Defect Dicubanes of $\left[\mathrm{LnIII}_{4}\left(\mu_{3}-\mathrm{OH}\right)_{2}(\mathrm{~L})_{4}(\mathrm{HL})_{2}\right] \cdot 2 \mathrm{THF}(\mathrm{Ln}=\mathrm{Gd}, \mathrm{Tb}$, Dy, Ho and Er). Polyhedron 2013, 66, 268-273 DOI: 10.1016/j.poly.2013.05.016.

(41) Gordon, R. J.; Campbell, J.; Henderson, D. K.; Henry, D. C. R.; Swart, R. M.; Tasker, P. A.; White, F. J.; Wood, J. L.; Yellowlees, L. J. Polyacidic Multiloading Metal Extractants. Chem. Commun. 2008, No. 39, 4801 DOI: 10.1039/b810610j.

(42) Chu, Y.-Y.; Kuo, H.-M.; Wu, Y.-C.; Wu, C.-Y.; Sheu, H.-S.; Lee, G.-H.; Chen, M.-C.; Lai, C. K. Catenar Bimetallomesogens Derived from Quinoxaline-salicylaldimine Conjugates. Tetrahedron 2014, 70 (14), 2389-2399 DOI: 10.1016/j.tet.2014.02.030.

(43) Pfeiffer, P.; Hesse, T.; Pfitzner, H.; Scholl, W.; Thielert, H. Innere Komplexsalze Der Aldimin- Und Azoreihe. J. Prakt. Chemie 1937, 149 (8-10), 217-296 DOI: 10.1002/prac.19371490801.

(44) Kishita, M.; Muto, Y.; Kubo, M. Subnormal Magnetic Moments of Some Copper Chelates. Naturwissenschaften 1957, 44 (13), 372-372 DOI: 10.1007/BF00629444.

(45) Barclay, G. A.; Hoskins, B. F. 356. The Crystal Structure of Acetylacetone-Mono-(O-Hydroxyanil) copper(II). J. Chem. Soc. 1965, 1979 DOI: 10.1039/jr9650001979.

(46) Ginsberg, A. P.; Sherwood, R. C.; Koubek, E. Magnetic Exchange in Transition Metal complexes-II Copper Complexes with Tridentate Schiff Bases. J. Inorg. Nucl. Chem. 1967, 29 (2), 353-365 DOI: 10.1016/0022-1902(67)80038-1.

(47) Spek, A. L. Structure Validation in Chemical Crystallography. Acta Crystallogr. Sect. D Biol. Crystallogr. 2009, 65 (2), 148-155 DOI: 10.1107/S090744490804362X.

(48) Wang, J.; Hanan, G. S. A Facile Route to Sterically Hindered and Non-Hindered 4'-Aryl-2,2': 6' 2 $^{\prime \prime}-$ Terpyridines. Synlett 2005, No. 8, 1251-1254 DOI: 10.1055/s-2005-868481.

(49) Beves, J. E.; Dunphy, E. L.; Constable, E. C.; Housecroft, C. E.; Kepert, C. J.; Neuburger, M.; Price, D. J.; Schaffner, S. Vectorial Property Dependence in bis $\left\{4^{\prime}-(N-P y r i d y l)-2,2^{\prime}: 6^{\prime}, 2^{\prime \prime}-\right.$ terpyridine 3 iron(II) and ruthenium(II) Complexes with $\mathrm{N}=2,3$ and 4. Dalton Trans. 2008, No. 3, 386-396 DOI: 10.1039/B714970K.

(50) Crawford, V. H.; Richardson, H. W.; Wasson, J. R.; Hodgson, D. J.; Hatfield, W. E. Relation between the Singlet-Triplet Splitting and the Copper-Oxygen-Copper Bridge Angle in HydroxoBridged Copper Dimers. Inorg. Chem. 1976, 15 (9), 2107-2110 DOI: 10.1021/ic50163a019.

(51) Bleaney, B.; Bowers, K. D. Anomalous Paramagnetism of Copper Acetate. Proc. R. Soc. A Math. Phys. Eng. Sci. 1952, 214 (1119), 451-465 DOI: 10.1098/rspa.1952.0181.

(52) Beves, J. E.; Constable, E. C.; Decurtins, S.; Dunphy, E. L.; Housecroft, C. E.; Keene, T. D.; Neuburger, M.; Schaffner, S.; Zampese, J. A. Structural Diversity in the Reactions of 4'-(Pyridyl)$2,2^{\prime}: 6^{\prime}, 2^{\prime \prime}$-Terpyridine Ligands and bis $\left\{4^{\prime}\right.$-(4-Pyridyl)-2, 2':6',2"-terpyridine $\}$ iron(II) with copper(II) Salts. CrystEngComm 2009, 11 (11), 2406 DOI: 10.1039/b909639f.

(53) Feyerherm, R.; Abens, S.; Günther, D.; Ishida, T.; Meißner, M.; Meschke, M.; Nogami, T.; Steiner, $M$. Magnetic-Field Induced Gap and Staggered Susceptibility in the $S=1 / 2$ Chain $\left[\mathrm{PM} \cdot \mathrm{Cu}\left(\mathrm{NO}_{3}\right)_{2} \cdot\left(\mathrm{H}_{3} \mathrm{O}\right)_{3}\right]_{\mathrm{n}}(\mathrm{PM}=$ Pyrimidine $)$. J. Phys. Condens. Matter 2000, 12 (39), 8495-8509 DOI: 10.1088/0953-8984/12/39/312.

(54) Chilton, N. F.; Anderson, R. P.; Turner, L. D.; Soncini, A.; Murray, K. S. PHI: A Powerful New Program for the Analysis of Anisotropic Monomeric and Exchange-Coupled Polynuclear D - and 
F -Block Complexes. J. Comput. Chem. 2013, 34 (13), 1164-1175 DOI: 10.1002/jcc.23234.

(55) Yahsi, Y.; Kara, H. Synthesis, Structural Analysis and Magnetic Properties of Two Novel Doubly Oxygen Bridged Binuclear manganese(III) and copper(II) Complexes with ONO Tridentate Ligands. Inorg. Chim. Acta 2013, 397, 110-116 DOI: 10.1016/j.ica.2012.11.029.

(56) Gleizes, A.; Maury, F.; Galy, J. Crystal Structure and Magnetism of Sodium bis(oxalato)cuprate(II)dihydrate, $\mathrm{Na}_{2} \mathrm{Cu}\left(\mathrm{C}_{2} \mathrm{O}_{4}\right) 2.2 \mathrm{H}_{2} \mathrm{O}$. A Deductive Proposal for the Structure of Copper Oxalate, $\mathrm{CuC}_{2} \mathrm{O}_{4} \cdot \mathrm{xH}_{2} \mathrm{O}$. Inorg. Chem. 1980, 19 (7), 2074-2078 DOI: 10.1021/ic50209a048.

(57) Berkheiser, V. Variability in Exchange Ion Position in Smectite: Dependence on Interlayer Solvent. Clays Clay Miner. 1975, 23 (5), 404-410 DOI: 10.1346/CCMN.1975.0230514.

(58) Ukpong, E. J.; Akpanudo, N. W.; Prasad, J. Redox and Spectral Behaviour of Copper (II)-Chloro and Bromo Complexes in Some Nonaqueous Solvents. African J. Pure Appl. Chem. 2010, 4 (4), 38-43.

(59) Vujovic, S.; Constable, E. C.; Housecroft, C. E.; Morris, C. D.; Neuburger, M.; Prescimone, A. Engineering 2D $\rightarrow 2 \mathrm{D}$ Parallel Interpenetration Using Long Alkoxy-Chain Substituents. Polyhedron 2015, 92, 77-83 DOI: 10.1016/j.poly.2015.03.010.

(60) Lü, J.; Han, L.-W.; Alsmail, N. H.; Blake, A. J.; Lewis, W.; Cao, R.; Schröder, M. Control of Assembly of Dihydropyridyl and Pyridyl Molecules via Directed Hydrogen Bonding. Cryst. Growth Des. 2015, 15 (9), 4219-4224 DOI: 10.1021/acs.cgd.5b00395.

(61) Zhang, X.-L.; Ren, C.-X.; Chen, X.-M.; Ng, S. W. Aqua\{1-[(2Oxidophenyl)iminomethyl]naphthalen-2-olato\}pyridinecopper(II). Acta Crystallogr. Sect. E Struct. Reports Online 2003, 59 (12), m1176-m1177 DOI: 10.1107/S160053680302631X.

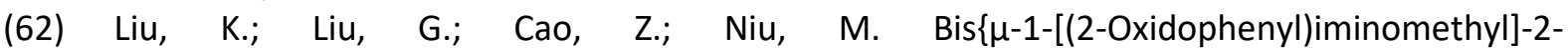
naphtholato\}bis[pyridinecopper(II)]. Acta Crystallogr. Sect. E Struct. Reports Online 2010, 66 (1), m78-m78 DOI: 10.1107/S1600536809053665.

(63) Coles, S. J.; Gale, P. A. Changing and Challenging Times for Service Crystallography. Chem. Sci. 2012, 3 (3), 683-689 DOI: 10.1039/C2SC00955B.

(64) CrysAlisPro, Agilent Technologies, Version 1.171.37.35 (Release 13-08-2014 CrysAlis171 .NET) (Compiled Aug 13 2014). p CrysAlisPro, Agilent Technologies, Version 1.171.3.

(65) CrystalClear-SM Expert 3.1 b27, Rigaku, 2013. p CrystalClear-SM Expert 3.1 b27, Rigaku, 2013.

(66) Palatinus, L.; Chapuis, G. SUPERFLIP - a Computer Program for the Solution of Crystal Structures by Charge Flipping in Arbitrary Dimensions. J. Appl. Crystallogr. 2007, 40 (4), 786790 DOI: 10.1107/S0021889807029238.

(67) Palatinus, L.; van der Lee, A. Symmetry Determination Following Structure Solution in P 1. J. Appl. Crystallogr. 2008, 41 (6), 975-984 DOI: 10.1107/S0021889808028185.

(68) Palatinus, L.; Prathapa, S. J.; van Smaalen, S. EDMA : A Computer Program for Topological Analysis of Discrete Electron Densities. J. Appl. Crystallogr. 2012, 45 (3), 575-580 DOI: $10.1107 /$ S0021889812016068.

(69) Sheldrick, G. M. SHELXT - Integrated Space-Group and Crystal-Structure Determination. Acta Crystallogr. Sect. A Found. Adv. 2015, 71 (1), 3-8 DOI: 10.1107/S2053273314026370.

(70) Sheldrick, G. M. A Short History of SHELX. Acta Crystallogr. Sect. A Found. Crystallogr. 2008, 64 (1), 112-122 DOI: 10.1107/S0108767307043930.

(71) Dolomanov, O. V.; Bourhis, L. J.; Gildea, R. J.; Howard, J. A. K.; Puschmann, H. OLEX2 : A Complete Structure Solution, Refinement and Analysis Program. J. Appl. Crystallogr. 2009, 42 (2), 339-341 DOI: 10.1107/S0021889808042726.

(72) Hunter, B. Rietica - A Visual Rietveld Program. Int. Union Crystallogr. Comm. Powder Diffr. Newsl. No. 20. 1998. 

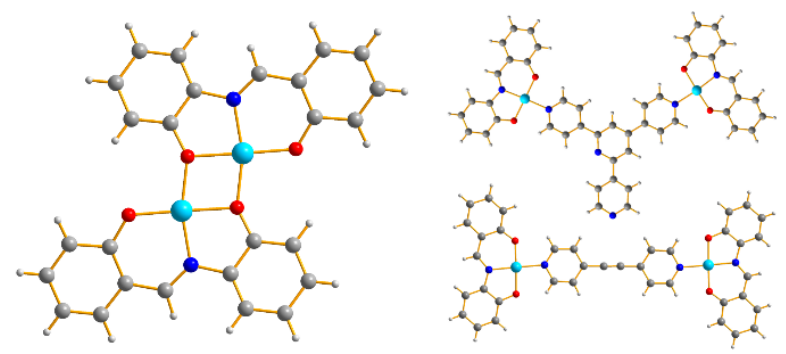

Dissolution of a one-dimensional coordination polymer in DMSO with 4,4'-bipyridine results in a new two-dimensional material where the coordination 'monomers' are now bridged, changing the connectivity and magnetic properties. Extending the bridging ligand family results in a series of discrete compounds of the monomer. We explore the limits of polypyridyls in bridging the monomers, finding a relationship between compound formation and polypyridyl solubility, allowing for the design of new coordination compounds of the monomer. 